\title{
PLANNING CITIES WITH WATER FRONTS: AN ACADEMIC INTERNATIONAL TEAM
}

\author{
A. Virtudes, A. Duarte, B. Ledes, L. Moura, L. Marinho \\ University of Beira Interior (PORTUGAL)
}

\begin{abstract}
The water fronts are sensitive areas, not only in environmental terms but also considering the continuity requirements with cities. Usually the spatial planning rules for the places of contact in between the urban fabric and water are focused on building issues and urban development questions rather than of ecological approaches. In this sense, this article aims to present solutions of rethinking the territories of contact in between cities and water fronts, having as pivotal concern, ecological solutions, friendly to the environment. The presented urban project is a requalification solution in order to promote the urban continuity from the buildings to the water, focused on river activities, sports and the preservation of architectural heritage.

The urban project solution has as case study, a small town in the central region of Portugal, which is very well known by its thermal baths, with roman roots. The city of São Pedro do Sul is a very pleasant place for holidays, being visited for those who are looking for improving their health condition going to the Thermal Care Centre, or the contact with nature going to the water front of Vouga river. This is a low-density place, where the majority of constructions are single houses, and the main architectural landmark is the old train station, a building from the $19^{\text {th }}$ century. Nowadays, there are no more trains arriving to São Pedro do Sul and the train track line is working as an ecological corridor for pedestrians and bicycles. However, besides this effort of improving the local environmental conditions, the contact of the city with the river is yet badly considered. There are still lots of urban voids, buildings in bad status of conservation or a lack of diversity and facilities in functional terms. The urban projects were designed in an academic background, comprising several teams of international students coming from Portugal, Greece, Brazil, Slovakia, Lithuania and Poland. A pioneer teaching methodology was tested at the Urban Planning Unit of the Master Degree in Architecture at the University of Beira Interior, as a result of an agreement with the local authority. The students were organized in groups in order to propose the urban design projects to the Train Station surroundings, ensuring the continuity of the urban fabric with the Vouga water front. The best projects won several pecuniary prizes, sponsored by the city hall, which was a stimulus for students along to the designing process. The conclusions show that the presented solution was concerned with strategies to preserve and to enhance the ecological identity of the place. This article will present the contents, options and solutions of the best urban project, designed by a team of students from Brazil and Portugal considered by the jury as the most ecological proposal, friendly of the natural features.
\end{abstract}

Keywords: Planning cities, Water fronts, Urban projects, International team, São Pedro do Sul, Vouga river.

\section{INTRODUCTION}

Nowadays, the importance of planning the cities is still a fundamental issue for the good development of local communities, urban neighbourhoods and their inhabitants. In an academic education framework, regarding the Urban Planning subjects, this knowledge is considered essential at both, the theoretical and the practical perspectives. When the case studies are focused on sensitive areas, such as those having spaces of contact between river water fronts and urban fabric, this knowledge is even more particular, in order to consider the features of these places. Besides the needs of creating green spaces, improving the connection of the city with the nature, via the water front, there is the need of create urban design solutions capable to provide the well-being of those who are enjoying such spaces. Doing this, here is a contribution to increase the quality of life of local communities, preserving and enhancing their local identity, in cultural, spatial or environmental domains. 


\section{METHODOLOGY}

The presented urban design project was the result of the Urban Planning Unit tasks, in the $4^{\text {th }}$ year of the Master Degree in Architecture at the University of Beira Interior, during the academic year of 2017/2018. The students were organized in several international groups, comprising different academic backgrounds, in order to gather in each team, the Portuguese and the international students. Therefore, the Portuguese speaking students (from Portugal and from Brazil) were put working together with the non-Portuguese speakers, coming from Greece, Poland, Slovakia and Lithuania, all of them attending to the referred Unit classes. There are several advantages of using this methodology considering the teaching-learning process of education. Among them there is the experience of language skills improvements in both idioms, Portuguese and English and the possibility of sharing different backgrounds, regarding the previous academic experiences from national and international students.

One of the most enthusiastic aspects during the academic semester was a result of the agreement established in between the University and the São Pedro do Sul city hall, in order to organize a contest with several prizes for the best urban design solutions, proposed by the students. The city hall has organized field trip for students to let them know very well the case study area, the train station surroundings near to Vouga river, and in the end of the academic process, the students were invited to present their projects in the city hall for its political and technical staff including the Mayor and for the local community as well.

In terms of the urban design process, the presented project refers to the winner proposal. It was projected by a team of Portuguese and Brazilian students. It seeks to find some guidelines to improve the connection of the river with the city, not only answering to the local citizens needs, but also to the visitor' expectations, being a place of harmony between inhabitants and visitors and the nature. It aims to propose solutions adapted to the young people needs and to the elderly population. In order to achieve these goals the solution proposes the creation of a river pool serving not only the local community but also the tourists, where they can enjoy such an important part of the place in a safe and pleasant manner. The urban requalification proposal for the train station surroundings aims to enhance the local activities, based on the space appropriation by the community. This work, has as a research process of analysis, a step based on the spatial planning rules in terms of building and urban development, regarding the national level of action and the particular level of the municipal realm. One of the considered spatial planning instruments is the São Pedro do Sul Master Plan and its contents for the case study area. In this way, a set of documents, such as maps, plans and written documents were gathered, in order to know all the building and urban development rules compulsory at the case study area, which should be follow by the urban design solution. This knowledge has allowed the team to continuing its work, considering all the required rules for the elaboration of the urban renewal project of the old railway station of São Pedro do Sul and its surroundings. Among those rules there was limitations, such as environmental protection requirements in certain parts of the case study area, urban restrictions or agriculture requirements.

In addition to the previously referred spatial planning ordinances, the methodology comprised a collection of several information gathered in loco, such as photographs and measurements, which were used as a database for this work. Finally, the methodological approach has considered the historical context of the place and the local landscape features, such as the Vouga river, studying their morphological aspects, habits and routines of the region and its population, in order to have a better understanding of the case study area. The competition organized by the city hall of São Pedro do Sul, was a great opportunity for students to try to do their best during the urban Planning Unit attendance. This kind of actions area considered by some authors [1] has instruments that promote the quality of the architecture, given that they prioritize the judgment of the projects over a set of the following criteria: the experience, the public recognition or the value of the service rendering. In addition to this, the contests are ways of affirmation of the performance of the ideas of student' teams, in a certain time and space [2]. 


\section{REQUALIFICATION PROJECT FOR THE TRAIN STATION SURROUNDINGS}

\subsection{Urban analysis}

The city of São Pedro do Sul, is located in the Portuguese District of Viseu and it is very well known for its thermal waters, that are used in health treatments and relaxation of the body. According to this main identity reference of the city, the urban requalification project starts from the principle of the experience of the presence of the water through the Vouga river, located in the case study field. The urban environments proposed at the project have a visual connection with the river, promoting a dialogue between the population on the surroundings neighbourhood and the Vouga river banks.

Regarding an analysis of some aspects of the city of São Pedro Sul, the team has verified that there is a large part of the local population, which is composed by elderly people. This aspect led the project options to adopt activities suitable for this group of inhabitants. In addition to these activities, the project solutions aim to attract more young people to the region. In order to achieve this goal the project proposes activities such as the following: water sports, picnic area, bike paths, and arts and crafts workshops. Since the region is surrounded by national agricultural and ecological reserves, where the building activity is restricted, according the contents of the Municipal Master Plan of São Pedro do Sul [3], the team has decided to propose green spaces to these areas, creating a water infiltration landscape. Regarding the housing, the project proposes low density buildings, plenty of outdoor leisure spaces, rather than large and tall buildings. The priority goes to the single-story buildings with only one floor high, in order to a better integration with the existing context.

The project prioritizes the use of construction materials that push to the natural textures, which are the reasons why the timber is used as the main structure for the project buildings, such as to the administration building, the support point for bicycles or to the new nautical centre, to be proposed by the Vouga river banks. According to the Portuguese national statistics institute (INE) in 2011 [4] the population of São Pedro do Sul comprised 15.970 inhabitants as a whole and 6.407 families (Table 1). Given that there were 11.662 accommodations. Therefore, is possible to conclude that some of them were empty or used as second house, comparing with the mentioned number of families. The elderly population (with 64 years old or more) corresponding to $27,80 \%$ was about three times more than the young people having until 15 years old (Figure 1) corresponding to $11,30 \%$ of the inhabitants as a whole.

Table 1: Local Data - São Pedro do Sul (Portugal) 2011 INE.

\begin{tabular}{c|c}
\hline \hline Population & 15.970 \\
\hline Men & 7010 \\
\hline Women & 8960 \\
\hline Families & 6407 \\
\hline Accommodation & 11662 \\
\hline Buildings & 10374 \\
\hline Parishes & 14 \\
\hline Population Density & 48,3 \\
\hline Maximum Altitude & $1119 \mathrm{~m}$ \\
\hline Surface & $349 \mathrm{~km}^{2}$ \\
\hline Birth rate & 6,3 \\
\hline \hline
\end{tabular}




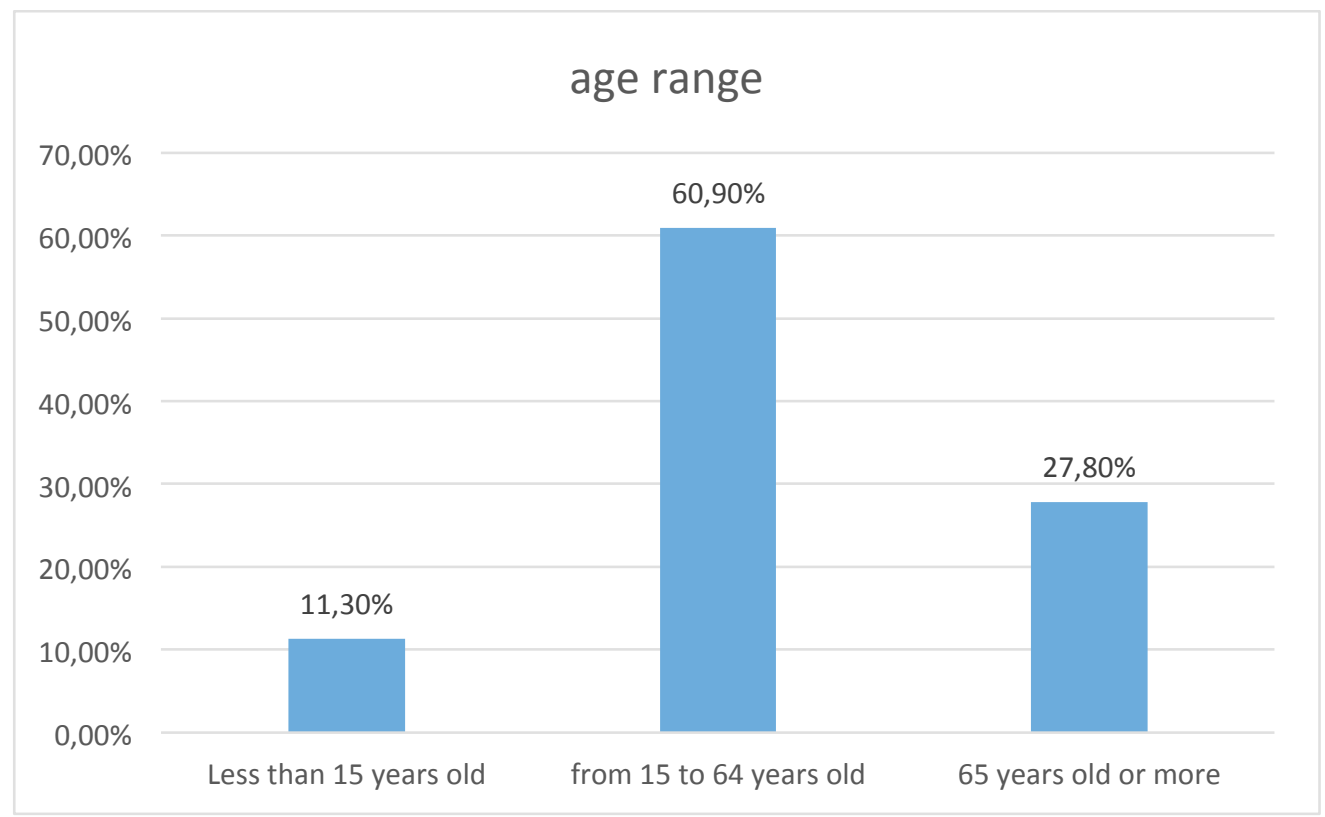

Figure 1: Age chart of the population - São Pedro do Sul (Portugal) 2011 INE.

\subsection{Project references}

\subsubsection{River Pool}

This project solution was inspired in some other project' references from different countries including Denmark and Brazil. One of these references is the urban design proposal used for the integration of a river pool at Vouga water front. The proposed pool was based on the design of the Bjarke Ingels Group Architects (BIG) architecture office at the city of Copenhagen, Denmark (Figure 2). This pool will be an icon of the case study area, which will turn from a degraded area to a culture and leisure trendy zone. From this reference, was possible to propose a novelty in the area, starting from the use of the Vouga river and the integration with the rest of its banks nearby. In addition to the pool, this project has proposed to have other elements composed by water, such as waterfalls along to the pedestrian and cycling paths. Given that sometimes there are floods on the Vouga river banks, the pool should be thought not only as a contemplative element, but also as a safe infrastructure to be used by visitors and inhabitants.

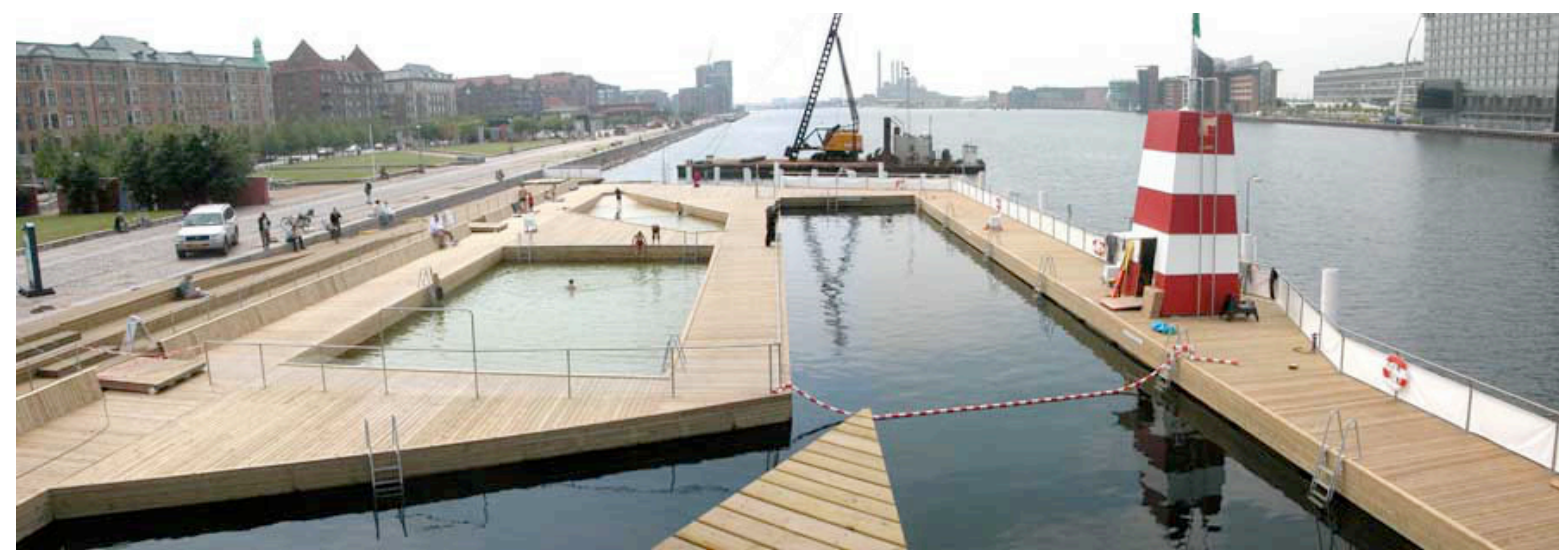

Figure 2: River Pool in Copenhagen, Denmark.

\subsubsection{Garden Stairs}

Another landmark of the urban requalification project as its inspiration at the experience of the capital city of Brazil, Brasília. The project belongs to the Brazilian artist, Burle Marx, and it is located in the Praça das Fontes square, which is one of the most complex urban components of the City Park. 
The Plaza das Fontes area has large green levels, where the volume of the steps allows not only the pedestrians to walk through the staircase, but also to stay there just having a seat or to carry on several activities related with greenery. The use of this reference will allow the project solution to be proposed, to turn a transition space composed by different levels regarding the sloppy existing terrain, into a more pleasant place. It could be used as a natural element plenty of greenery. Thus, the population will be able to give a glimpse upon the beautiful view of the Vouga river, with room for outdoor activities related with leisure, such as picnics or sunbathing.

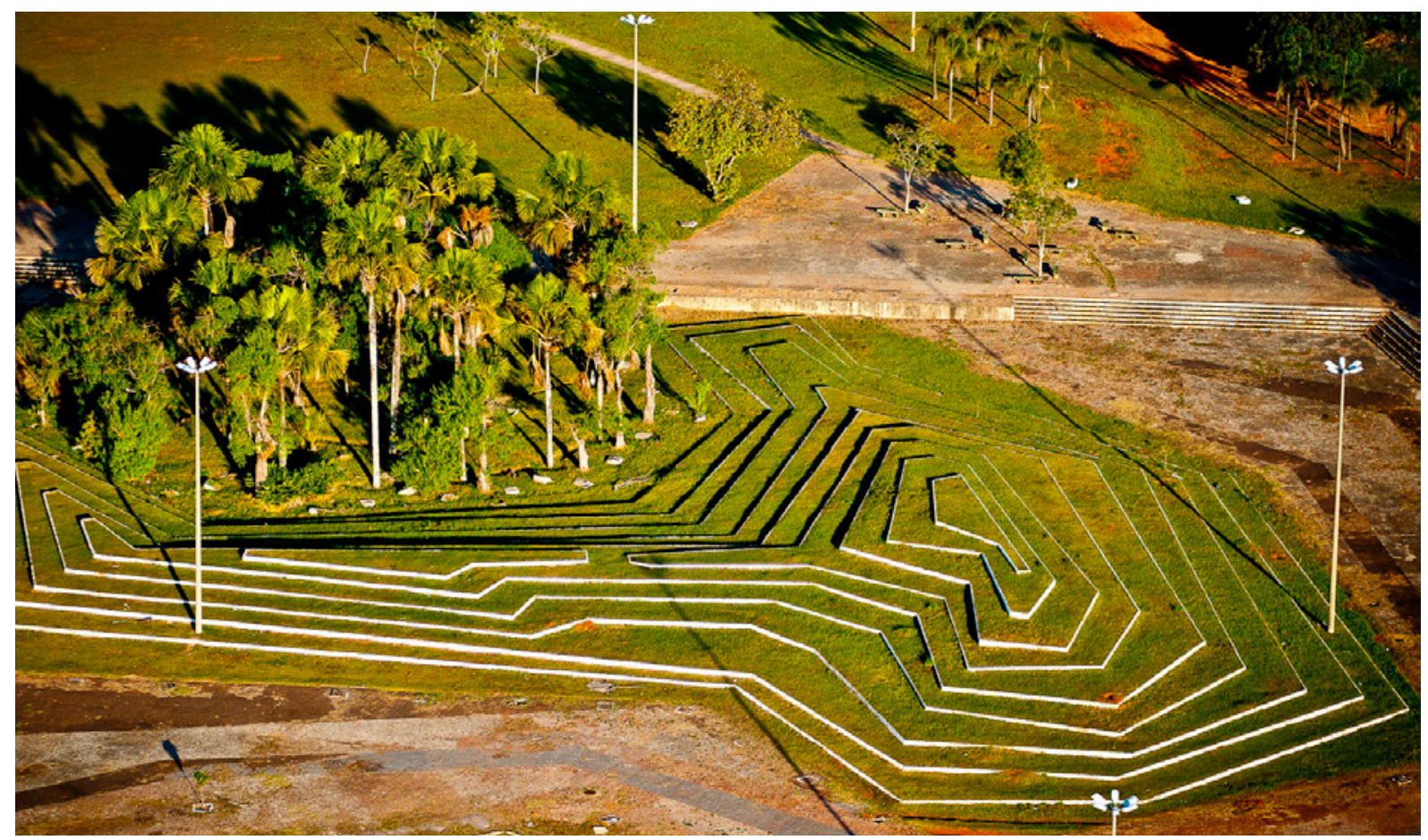

Figure 3: Praça das Fontes square in Brasilia, Brazil.

\subsubsection{Centre for Artistic Creation Workshops}

The creation of an artistic centre for creation workshops is one of the objectives of the urban design project. In order to achieve this goal the idea is to reuse of the nineteen-century train station building as a historical and architectonic landmark, turning it into a centre for the arts, for learning and for practicing several creation activities. The train station will be the house for cultural activities including workshops, production of art and an art gallery.

The reference for the creation of this urban element comes from the SESC Pompeia (Figure 4), located in the city of São Paulo, in Brazil. It refers to a social building where there are several incentives for sports, art and training of the population, through a particular environment, created by the reuse of an old industrial building, converted into an artistic centre. The transformation included the refurbishment of the building, which has become very popular all over the region, very well known by its art activities. 


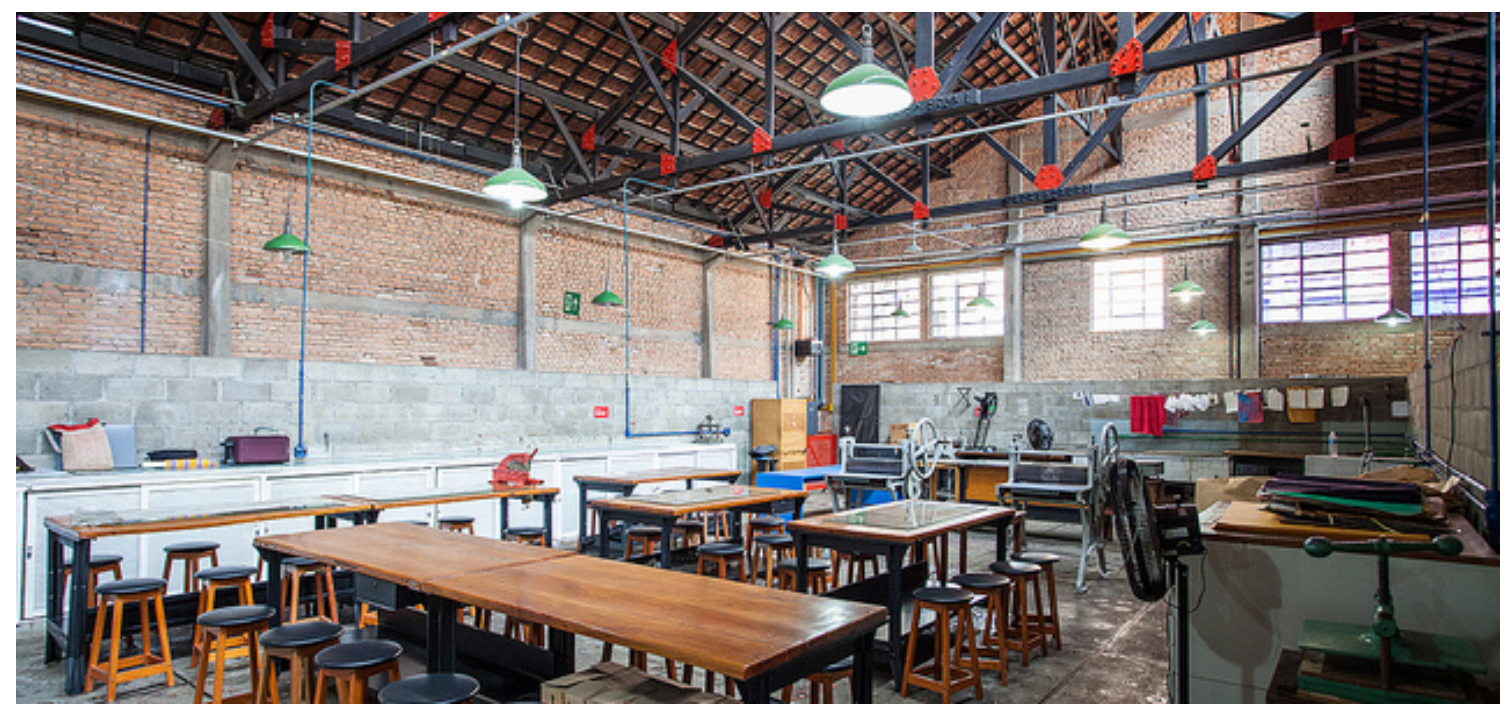

Figure 4: Sesc Pompeia, Arts Centre in São Paulo, Brazil.

From the idea of the social projects that SESC Pompeia house, the project for São Pedro do Sul will proposed something identic to the train station, in order to encourage and to promote the art not only among the city inhabitants but also all over the region.

\subsection{Urban design project proposals}

Developed for the location of the old railway station of São Pedro do Sul, the project seeks to insert a new point of activities in the municipality, combining new uses in order to integrate the different groups of the population, as well as the urban environment and the Vouga river, permeating the different strategic points of the locality and potentiating a new space for the city. This project main landmarks are the following: the old train station building, the Vouga river pool, the nautical centre, the stairs garden, and the outdoor amphitheatre.

\subsubsection{Old Train Station}

This project proposes a new function for the old train station building. The idea is to turn this building into an arts centre working as a cultural meeting point. It will include a small cafeteria, and it will mainly be working as an Artistic Centre of Creation and Workshops for the local community, in order to stimulate the arts and local interaction among the inhabitants, and visitors (Figure 5).

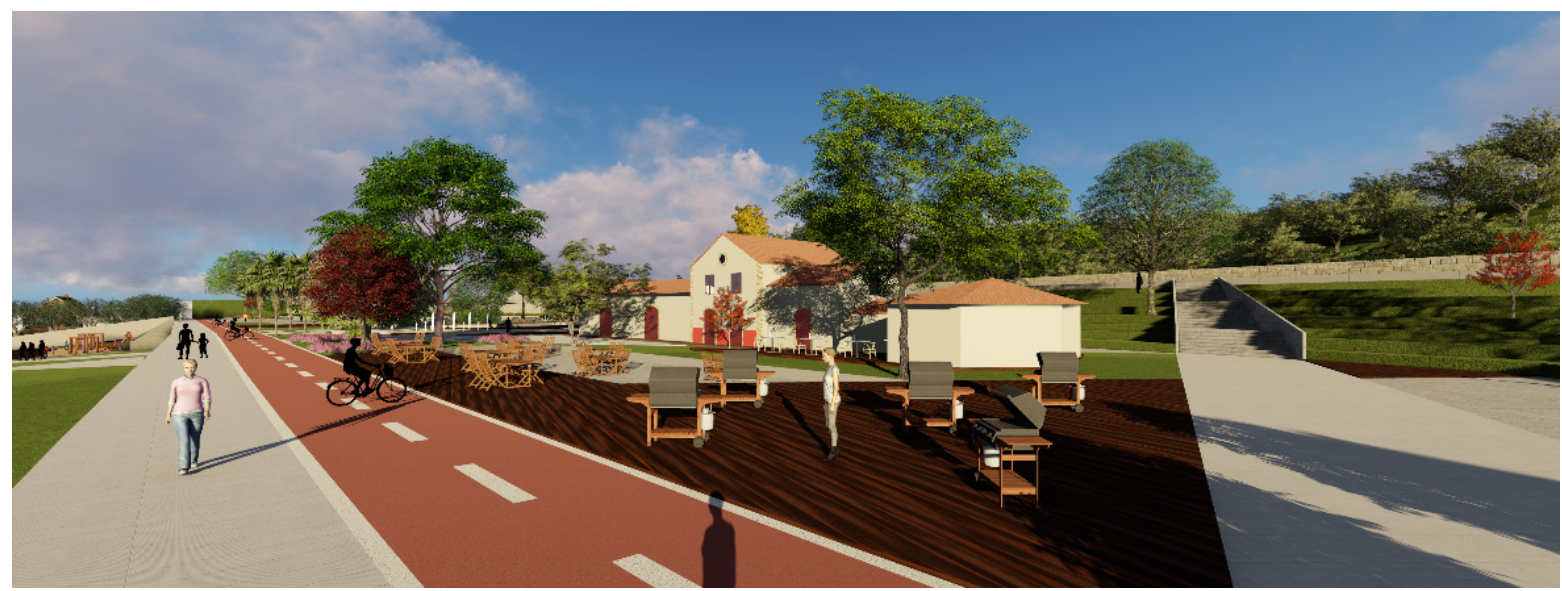

Figure 5: Urban design project: the Arts Centre at the old Train Station building, São Pedro do Sul.

\subsubsection{River Pool}

The creation of a Vouga river pool has aroused in such a way as to attract the population to the Vouga river banks, in a safe and controlled manner. Its advantage is to present a low environmental impact and to allow its use by a great diversity of people of different ages and conditions. The chosen 
construction material for the river pool is the wooden slats, given that they will allow a visual continuity with the green park and they will also act as a large space of permanence for the users, contacting with water and nature (Figure 6).

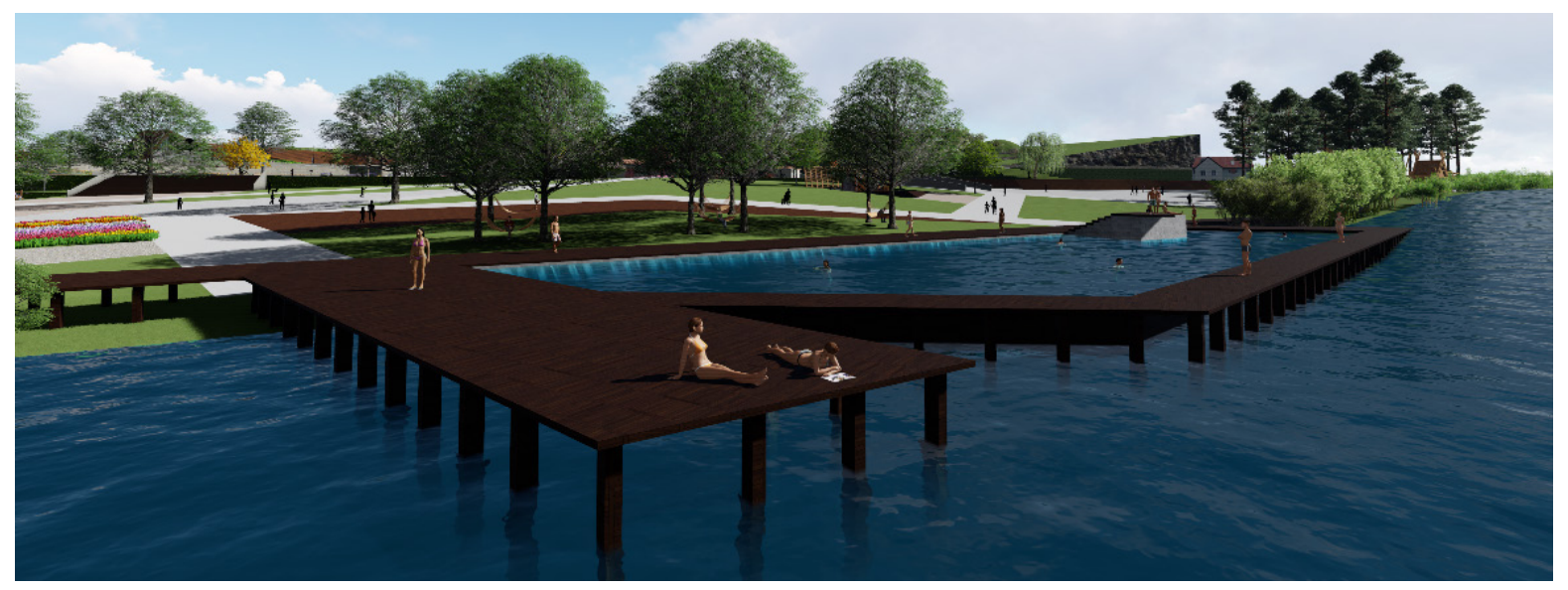

Figure 6: Urban design project: Vouga river Pool, São Pedro do Sul.

\subsubsection{Nautical Centre}

One of the city hall requirements for the urban design projects was the creation of a Nautical Centre, in order to boost the river activities related with leisure and sports. Therefore, it emerges in this urban design solution as the main architectonic icon that supports the water sport activities, housing the equipment regarding canoeing, kayaking among others. The building will be integrated with a wharf, which allows the anchorage of small boats. The pier will work as well as the access point to the park for those who are entering to this area from the river (Figure 7).

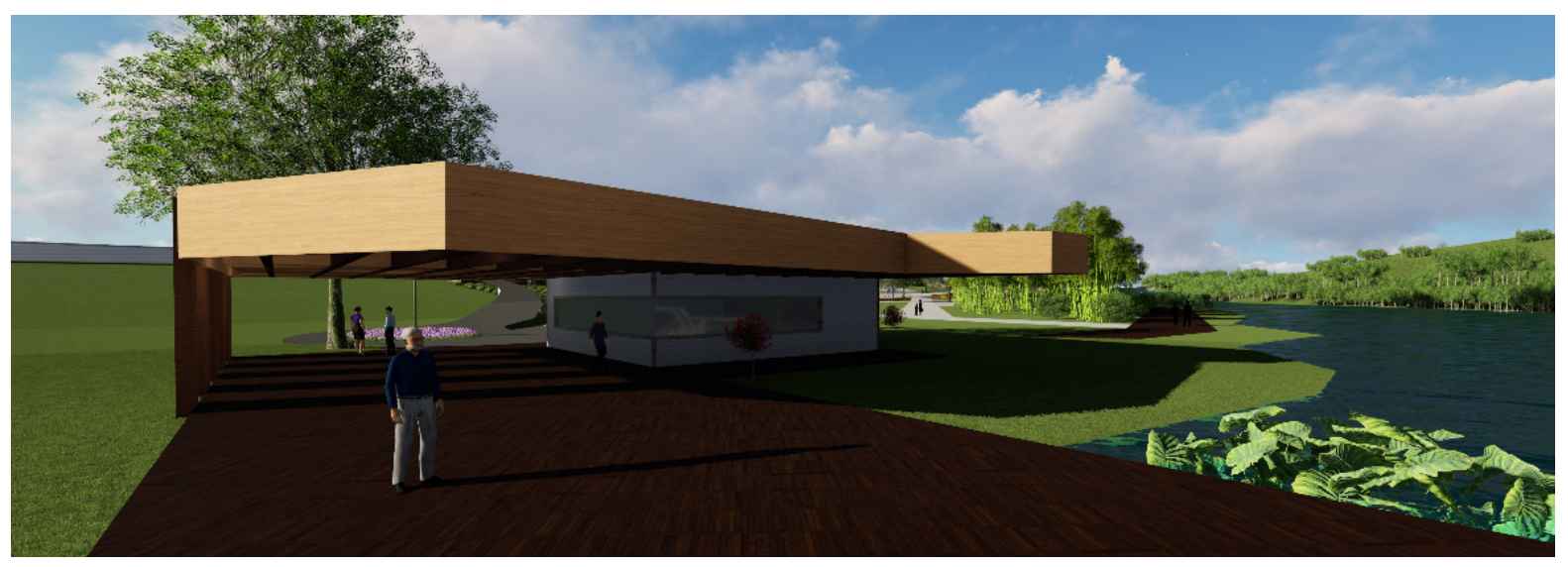

Figure 7: Urban design project: Nautical Centre, São Pedro do Sul.

\subsubsection{Stairs Garden}

The project proposes a stairs garden inspired on the previously referred example of São Paulo. It will be a landscape connecting a pleasant green space with the iconic building of the train station. It aims to be an iconic reference in aesthetic terms not only for the city but also for all the region. It will be a place for permanence, contemplation, contact with different species of plants and natura (Figure 8). 


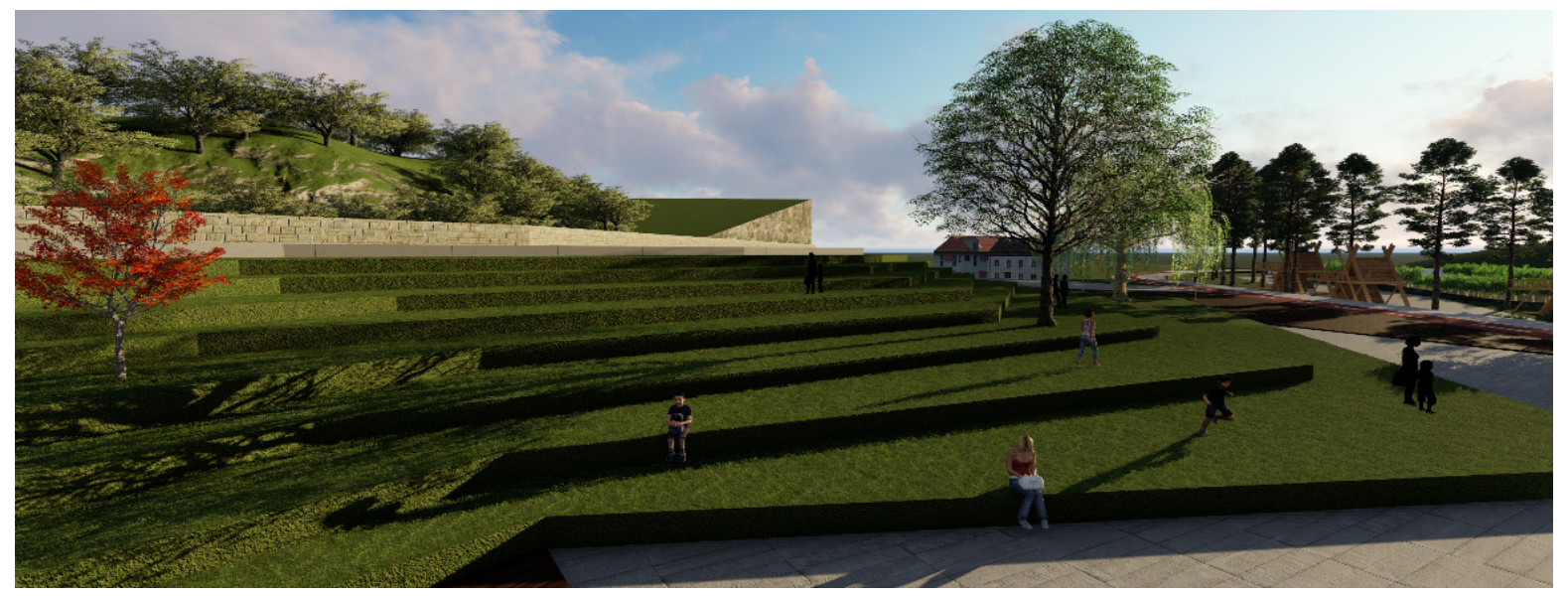

Figure 8: Urban design project: Stairs Garden, São Pedro do Sul.

\subsubsection{Outdoor Amphitheatre}

An outdoor Amphitheatre is proposed for the case study area. It will be used for several cultural or musical events, or theatre performances (Figure 9).

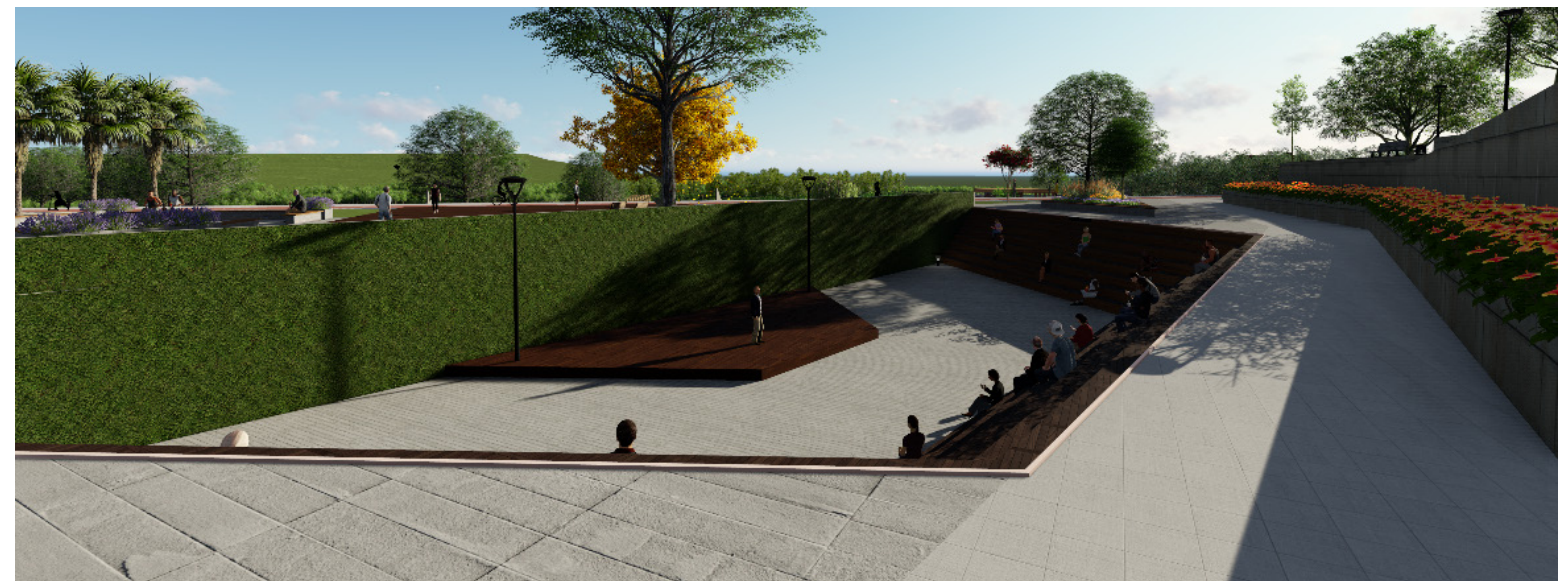

Figure 9: Urban design project: Outdoor Amphitheatre, São Pedro do Sul.

\subsubsection{Other relevant aspects}

The solution proposes an annex building to be used as support for the Arts Centre and Creation Workshop. It will house the administration services, and some rooms for art gallery. Its architecture will be based on timber structures, because they have great structural lightness and a better performance than other materials. The timber as its main construction material will allow a greater agility and volumetric freedom (Figure 10).

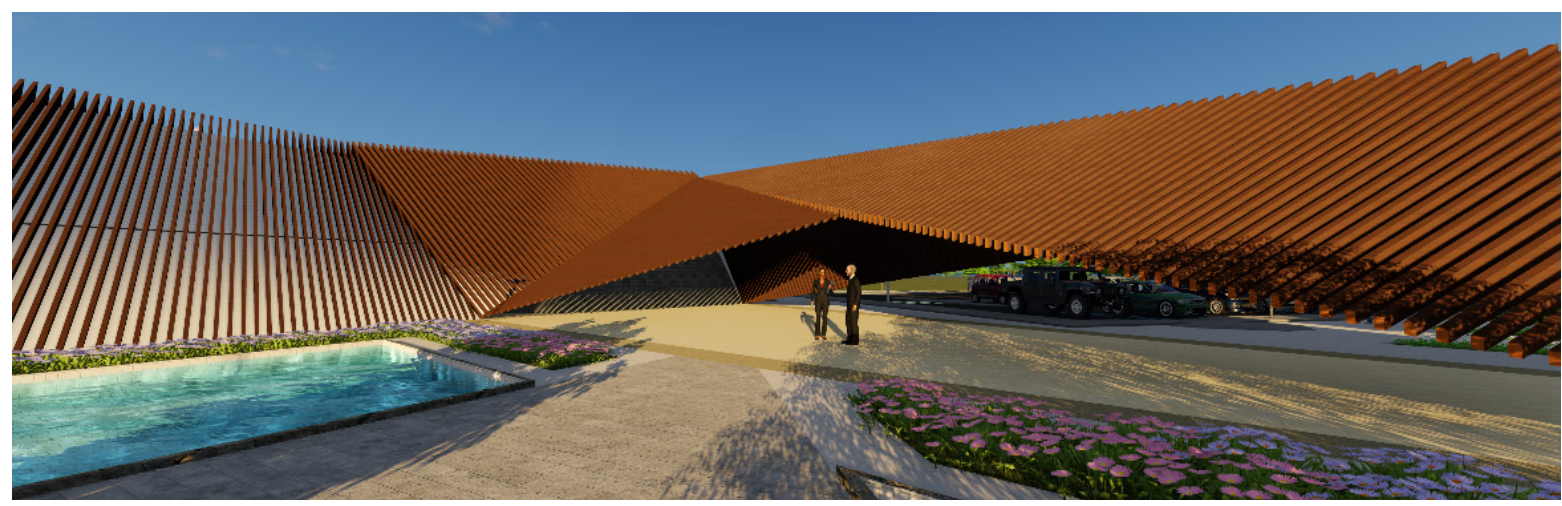

Figure 10: Urban design project: Annex Building, São Pedro do Sul. 
This urban design solution, proposes a total of three main public buildings for facilities, spread all over the train station surroundings. These elements will include public use bathrooms, benches, water fountains and bike racks.

Other relevant elements of the proposal include a public car park with 88 parking places, a playground for children, a deck under the bridge over Vouga river, a camping park area and a community garden.

In methodological terms the urban design project process can be organized in two main stages. The first of them was focused on the very near surroundings of the train station building (in red at Figure 11). The second was focused on a bigger area, linking the pre-existing urban fabric with the Vouga river water front (in yellow at Figure 11).

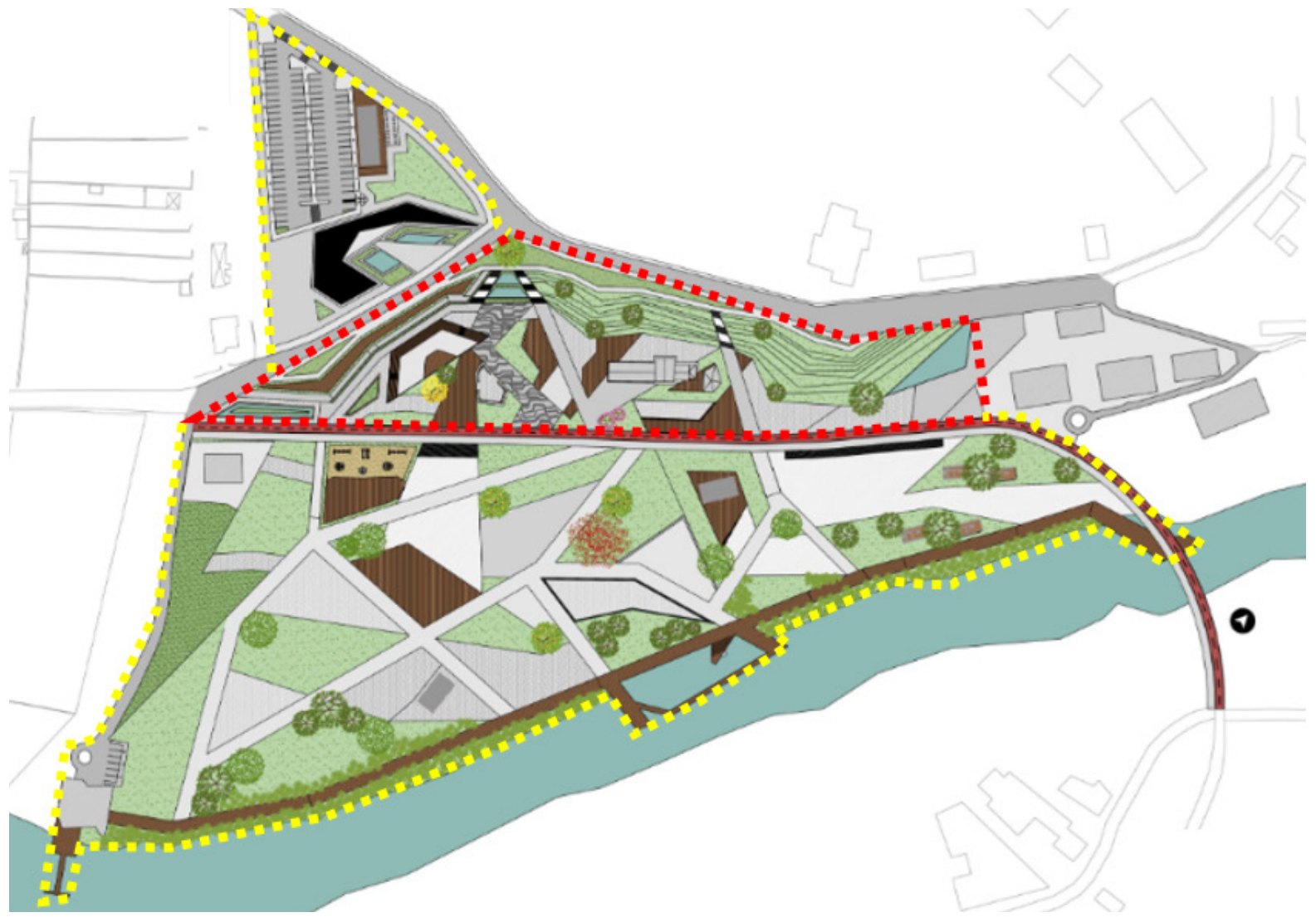

Figure 11: Urban design project: First phase of the solution (in red); Second phase of the solution (in yellow), São Pedro do Sul.

\section{CONCLUSIONS}

Among to the main conclusions is the fact that the agreement in between the São Pedro do Sul city hall and the university of Beira Interior team, regarding the Unit of Urban Planning at the $4^{\text {th }}$ year of the Master Degree in Architecture was the main responsible for the high level of motivation among the students during the urban design process.

Another relevant aspect, to the stressed is the methodological approach considered at the Unit in order to organized multicultural teams, comprising students coming from different countries with different academic backgrounds. This aspect has definitely contributed to rise the quality of the urban design solutions, with a wider range of references. Regarding the presented urban design project, its main importance comes from the several facilities which are projected, offering to the São Pedro do Sul inhabitants a wide range of activities, contacting with the Vouga river water front. It has a particular focus on the cultural activities with the Arts Centre and the Outdoor Amphitheatre and at the Vouga river sports with the Nautical Centre. The planning area has been designed in order to welcome not only the local residents, but also the visitors, creating a new centrality in the city. The proposal aims to solve some identified problems, with emphases on the lack of facilities. Therefore, a strong point of this project is to highlight the case study area landmarks, such as the old train station building, which will turn into an Arts Centre, the main icon for cultural and leisure activities; and the Vouga river 
waterfront, which will become the more important natural element of the case study area, with the pool and the water sports infrastructures.

Another aspect is the creation of green spaces, which will be used not only because of their greenery, but also because of their aesthetics quality, such as the Stairs Garden. They will promote a contact with nature, providing activities of contemplation, walking and entertaining, always offering an easy access for all, and a visual glimpse over the landscape. In a word, the presented urban design solution has intended to improve the urban features of the train station surroundings, by adding some points for a great diversity of activities, without proposing a deep changing regarding the previous situation. The project was based on a better appropriation of the space by the local community, regarding the place potentials. Finally, the competition organized by the city hall offering monetary prizes to the five best solutions, was a pivotal motivation for the efforts of the students during the semester, being working several more hours with the Urban Planning Unit teacher, than the classes hours of the official schedule. The presented urban design solution has won the first prize at this competition.

\section{ACKNOWLEDGEMENTS}

This publication was supported by the C-MADE, the Centre of Materials and Building Technologies, University of Beira Interior, Covilhã, Portugal, financed by FCT, the Portuguese Foundation for Science and Technology.

\section{REFERENCES}

[1] F. Sobreira, Design Competitions in Brazil - Building a [Digital] Culture for Architectural Quality. In: CHUPIN, J.; CUCUZZELLA, C.; HELAL, B. (Org.) Architecture competitions and the production of culture, quality and knowledge - An international inquiry. Montreal: Potential Architecture Books, 2015.

[2] J. Chupin, A world of potentialities - Competitions as producers of culture, quality and knowledge. In: CHUPIN, J.; CUCUZZELLA, C.; HELAL, B. (Org.) Architecture competitions and the production of culture, quality and knowledge - An international inquiry. Montreal: Potential Architecture Books, 2015.

[3] Municipal Master Plan of São Pedro do Sul. Land uses map (1:25000). São Pedro do Sul: City Hall.

[4] Portuguese National Statistics Institute, INE, 2011. 